\section{Commentary: Lake Wobegon guidelines reach Lake Erie}

\author{
Craig R. Smith, MD
}

Johnstone and colleagues ${ }^{1}$ are justifiably proud of their outstanding results in low-risk surgical aortic valve replacement (SAVR). As we've come to expect from the Cleveland Clinic, the statistical analysis is probing and impeccable. They conclude that the Society of Thoracic Surgeons risk model "substantially overestimates actual SAVR risk in a high-volume center." Their stated goal is to provide "a benchmark for transcatheter AVR" that links to their introductory sentence about guidelines for treatment of low-risk patients with aortic stenosis. The clear implication is that guidelines should take into account the outstanding results at the Cleveland Clinic before recommending transcatheter AVR to lowrisk patients: "Patients, in particular, deserve to understand not only what constitutes an average outcome, but also what is potentially achievable in minimizing their risk." The Cleveland Clinic would prefer to be the benchmark.

Are guidelines standing in the way of what patients deserve? Should guidelines be based on average practice, best practice, or both? Both seems the obvious choice, but best-practice claims typically rest on single-institution or single-surgeon series. That presents guidelines writers with the challenge of weighting each report without being misled by bias or flaws in analysis; not every institution has the analytical capabilities of the Cleveland Clinic. An indirect approach is for guidelines to emphasize confidence intervals in representations of average practice to provide readers with a sense of what best looks like compared with the mean. Unfortunately, even average SAVR has a

\footnotetext{
From the Department of Surgery, Vagelos College of Physicians and Surgeons of Columbia University, Columbia University Irving Medical Center of New York Presbyterian Hospital, New York, NY.

Disclosures: The author reported no conflicts of interest.

The Journal policy requires editors and reviewers to disclose conflicts of interest and to decline handling or reviewing manuscripts for which they may have a conflict of interest. The editors and reviewers of this article have no conflicts of interest.

Received for publication Feb 8, 2021; revisions received Feb 8, 2021; accepted for publication Feb 9, 2021; available ahead of print Feb 18, 2021

Address for reprints: Craig R. Smith, MD, Department of Surgery, Vagelos College of Physicians and Surgeons of Columbia University, Columbia University Irving Medical Center of New York Presbyterian Hospital, Milstein Building 7-435, 177 Fort Washington Ave, New York, NY 10032 (E-mail: crs2@cumc.columbia. edu).

J Thorac Cardiovasc Surg 2023;165:605

$0022-5223 / \$ 36.00$

Copyright (c) 2021 by The American Association for Thoracic Surgery

https://doi.org/10.1016/j.jtcvs.2021.02.033
}

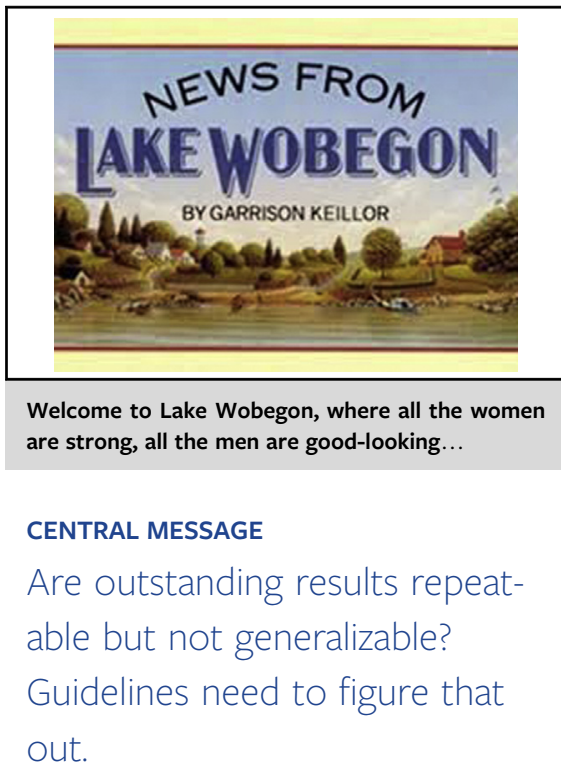

relatively low frequency of bad outcomes, and confidence intervals are rather narrow, so even the Cleveland Clinic's results may not impress the average reader enough to understand what he or she deserves.

The authors have drawn a sharp distinction between generalizable and repeatable results. Readers like me who aren't sure there is a critical difference are set straight. Repeatable results are those achievable by institutions who adopt Cleveland Clinic's best practices, and generalizable results are what everyone else gets.

My quibbles with the authors' style should not divert attention from their truly outstanding results, and I agree that positive outliers present a significant challenge to guidelines. However, no center of excellence, or even a group of them, can do every SAVR in the world. Furthermore, transcatheter AVR might be clearly superior to SAVR, or the other way around, in the local/regional aortic valve ecosystems occupied by patients who can't shop for alternatives. Does that represent the best of all possible worlds? Perhaps not, and for the authors to lead with outcomes and best practices to which all surgeons can aspire is a valuable contribution. In the meantime, relatively low average SAVR risk combined with narrow confidence intervals helps ensure that a patient operated on by a local surgeon on a good day is likely to do just as well as he would on a fair day in Cleveland.

\section{Reference}

1. Johnstone DR, Mahboudi R, Soltesz EG, Artis AS, Roselli EE, Blackstone EH, et al. Redefining "low risk:" outcomes of surgical aortic valve replacement in low-risk patients in the transcatheter aortic valve replacement era. J Thorac Cardiovasc Surg. 2023;165:591-604.e3. 